\title{
O PNLD Língua estrangeira e a produção oral no LD de Inglês
}

\section{The foreign Languages National textbook program (PNLD) and oral production in English didactic books}

\author{
Raquel Santos Lombardi'; Marta Cristina Silva ${ }^{2}$
}

\begin{abstract}
Resumo
Este trabalho tem por objetivo investigar como a produção oral é abordada num livro didático, aprovado pelo PNLD (Programa Nacional do Livro Didático - 2011: Língua Estrangeira Moderna), em comparação com os parâmetros estabelecidos pelo próprio Programa. Dentre os dados coletados, o presente estudo focaliza a análise da seção que é especificamente voltada ao desenvolvimento das habilidades de produção oral. Com base na pesquisa documental e assumindo uma visão sociocultural de linguagem, discutimos em que medida as atividades apresentadas no livro didático contribuem para a formação de falantes de inglês, que sejam capazes de responder/reagir, adequadamente, aos vários gêneros orais que circulam em suas práticas sociais. Os resultados apontam que predominam, os textos criados, exclusivamente, para fins didáticos, e a abordagem do oral parece fundamentada em uma visão, ainda, tradicional de ensino de língua.
\end{abstract}

Palavras-chaves: PNLD. Livro didático. Produção oral.

\section{Summary}

This work aims at investigating how oral production is approached in an English textbook approved by the PNLD (National Textbook Program - 2011: Foreign Languages) as compared to the guidelines which the PNLD itself establishes. Among the data collected, the current study focuses on the analyses of a section which is specifically devoted to the development of oral production skills. Based on documentary research and assuming a sociocultural view of language, we discuss to what extent the tasks presented in the textbook contribute to the formation of English speakers capable of responding/ reacting properly to the various oral genres circulating in their social practices. The results show that texts created exclusively for educational purposes predominate, and the oral approach seems grounded in a still traditional view of language teaching.

Keywords: PNLD. Textbook. Oral production.

\footnotetext{
${ }^{1}$ Possui licenciatura em Letras (Português/ Inglês) e bacharelado em Letras: Ênfase em Tradução-Inglês pela Universidade Federal de Juiz de Fora. Atualmente, é Mestre em Linguística pelo Programa de Pós-Graduação em Linguística da Universidade Federal de Juiz de Fora e doutoranda em Linguística pelo mesmo Programa. E-mail: raquellombardi@yahoo.com.br

${ }^{2}$ Doutora em Letras. Professora do Departamento de Letras Estrangeiras Modernas da Faculdade de Letras da UFJF. Atua na graduação, na área de língua inglesa, e no Programa de Pós-Graduação em Linguística, na linha de pesquisa Linguística e ensino de língua. E-mail: martacris.silva@gmail.com.
} 


\section{Introdução}

Os papéis e as funções do livro didático no ensino sempre foram alvo de debates, sejam no campo de língua materna ou de língua estrangeira, que será o nosso foco no presente trabalho, podendo-se abordar a questão sob diversos ângulos. O que não se pode deixar de considerar é que, como apontam Tilio (2012), Pinto e Pessoa (2009), Ramos (2009) e Siqueira (2012), apesar de o livro didático (doravante LD) ser adorado por uns e repudiado por outros, esse tipo de material está, de fato, inserido no cenário educacional brasileiro, constituindose numa das principais fontes de informação, bem como de transmissão de conhecimentos, no âmbito do processo de ensino-aprendizagem de línguas. Mais do que simples recurso pedagógico, o LD tem ocupado um lugar central no contexto da sala de aula, tanto como suporte aos alunos, quanto apoio fundamental na própria formação dos professores: "não raro, os livros didáticos correspondem à única fonte de consulta e de leitura dos professores e dos alunos" (PINTO; PESSOA, 2009, p. 79).

No campo do ensino de língua estrangeira, sabese que o LD nem sempre esteve presente na sala de aula das escolas públicas da educação básica, sendo, frequentemente, adotado apenas por instituições particulares. Com a implementação do PNLD, que estabeleceu parâmetros rigorosos de avaliação, não só passou a haver a distribuição gratuita desses livros para os alunos da escola pública, como ocorreram mudanças significativas na forma de concepção e de apresentação desse material didático. É, hoje, consenso que houve um considerável avanço, em consonância com novas perspectivas linguísticas e pedagógicas; há questões, entretanto, que ainda precisam ser problematizadas.

Tendo em vista o escopo deste trabalho, nosso objetivo será focalizar o tratamento dado à produção oral, em um LD de língua estrangeira do ensino fundamental. Mais especificamente, buscaremos estabelecer um contraponto entre o que o PNLD 2011 elege como critério para a produção oral e a abordagem, efetivamente, proposta por um dos LD aprovados pelo Programa.

Para subsidiar nossa discussão, faremos, a seguir, uma breve análise do próprio PNLD e da concepção de produção oral subjacente ao Guia do PNLD 2011 de Lingua Estrangeira (BRASIL, 2010).

\section{O PNLD - 2011 - Língua Estrangeira}

\section{Moderna: Impactos Político-pedagógicos}

Segundo o portal do MEC, o PNLD tem como objetivo principal "subsidiar o trabalho pedagógico dos professores, por meio da distribuição de coleções de livros didáticos aos alunos da educação básica", sendo o mais antigo dos programas voltados aos estudantes da rede pública de ensino brasileiro". (BRASIL, 2013b). Todavia, somente nos Editais de 2008 e 2009, foi incluído, na área de Linguagem, Códigos e suas tecnologias, o componente língua estrangeira moderna, resultando no Guia de Livros Didáticos: PNLD 2011 - Língua Estrangeira Moderna (BRASIL, 2010), no qual temos quatro coleções didáticas aprovadas, duas de língua inglesa e duas de língua espanhola (do total de 37 coleções submetidas à avaliação, sendo 11 de espanhol e 26 de inglês).

A inserção do componente Língua Estrangeira Moderna é algo extremamente significativo para a educação brasileira. De acordo com Vial e Silva (2012), esta inclusão "significa um grande avanço nos rumos da formação em educação linguística, pois o papel da Língua Estrangeira Moderna na educação básica está sendo, finalmente, reconhecido" (VIAL; SILVA, 2012, p. 110). Essa questão toma grandes proporções, ainda, se pensarmos na questão da universalização da distribuição do LD de inglês para a rede pública, pois, com o PNLD 2011, passou a ser disponibilizado, para cada aluno da rede pública, um livro consumível das disciplinas de Espanhol ou Inglês, acompanhado de um CD de áudio; isto é, o aluno agora possui, de fato, o LD, podendo nele escrever e não sendo mais necessário devolvê-lo à 
escola. Isso constitui, certamente, uma conquista, um ganho importante para a história do ensino de língua estrangeira nas escolas públicas brasileiras.

O PNLD se configura, dessa forma, como um programa com um notável potencial, sendo algo capaz de sugerir novos rumos para o ensino, para a rotina escolar. Mudanças significativas já foram empreendidas, entretanto, sabemos que, ainda, há um longo caminho a percorrer. Existem vozes dissonantes concernentes à relevância e eficácia do PNLD. Não podemos esquecer de que há aspectos políticos, econômicos e, até mesmo ideológicos, em certa medida, envolvidos na seleção das obras a serem utilizadas pelas escolas. É sabido que as grandes editoras não costumavam se aproximar do setor público. Com a inclusão da língua estrangeira no PNLD 2011, porém, essa situação se reverteu, e os grandes nomes do mercado editorial se voltaram para os LD de língua estrangeira destinados à educação básica. Isso se mostra bastante positivo, por um lado, mas não pode obscurecer o fato de que há outros interesses em jogo, que não apenas a melhoria do processo de ensino-aprendizagem.

O PNLD sofre críticas, ainda, no que concerne ao seu caráter fortemente avaliativo e eliminatório, visto que, como se sabe, os critérios de seleção dos LD são extremamente rígidos, podendo levar à eliminação das obras. A adequação do PNLD no território brasileiro, como um todo, também, evidencia-se como uma questão a ser discutida. Será que um mesmo LD é capaz de atender às necessidades de alunos provenientes de diferentes regiões do país? Essa questão foi levantada, por Cristovão (2013), em uma conferência ${ }^{3}$ que abordava, entre outros temas, a questão do material didático via PNLD. Cristovão investiga a possibilidade e a viabilidade de um programa local voltado ao LD, com direcionamentos menos amplos, visando, assim, a um público mais específico. Essa questão, ainda, se configura como um campo aberto para estudos e pesquisas mais aprofundadas, uma vez que há que se considerar, também, o custo financeiro de uma iniciativa desse tipo para os cofres públicos.

Seja como for, acreditamos que, mesmo com essas ressalvas, ao estabelecer parâmetros de avaliação dos livros didáticos que acabam norteando os objetivos do ensino de línguas, o PNLD pode auxiliar no processo de transposição didática de determinados conceitos. Dito de outro modo, os critérios do PNLD podem guiar, de certa maneira, a transposição de um dado conhecimento científico a um conhecimento a ser ensinado. Machado e Cristovão (2006) abordam essa questão, ao teorizarem sobre a construção de material didático adequado para o ensino de gêneros:

No Brasil, após a promulgação dos PCN [...], a obediência aos parâmetros também passou a ser uma exigência para a aprovação dos livros didáticos submetidos à avaliação do Programa Nacional do Livro Didático (PNLD). Assim, [...], estamos diante de um subnível da transposição dos conhecimentos científicos a conhecimentos a serem ensinados, sendo ele, talvez, o mais importante, pois, no caso brasileiro, as prescrições dos documentos e o trabalho real do professor são mediados pelos livros e materiais didáticos (MACHADO; CRISTOVÃO, 2006, p. 556).

Não deixamos de considerar, no entanto, que, em sua prática didático-pedagógica, o professor é plenamente capaz de alterar/adequar a proposta presente no livro didático, aperfeiçoando-a, reestruturando-a. Estamos cientes de que a adoção de um livro aprovado pelo PNLD, por si só, não assegura a qualidade do trabalho desenvolvido em sala de aula. Ao mesmo tempo, o professor não pode ser considerado um ser acrítico. Nesse sentido, defendemos que o professor, se bem informado teoricamente, tem condições de agir de forma ativa frente ao $\mathrm{LD}$, estando este a serviço daquele e não o contrário.

\footnotetext{
${ }^{3}$ Conferência intitulada "Caleidoscópio nas letras: múltiplos olhares para a educação de professores de língua", proferida no dia 21 de novembro de 2013 como parte da Semana de Letras da Universidade Federal de Juiz de Fora.
} 
Através da avaliação bastante criteriosa do LD de língua estrangeira, o Programa permite que o material didático selecionado seja, segundo Costa (2011, p. 320), um "livro concebido metodologicamente de modo que os textos e as atividades possibilitem a aprendizagem efetiva da leitura, escrita, audição e fala em LE na escola, numa perspectiva crítica e reflexiva, contribuindo, assim, para a formação da cidadania". A autora pontua, ainda, que tal dimensão do tipo de material didático exigido vai ao encontro da questão da construção da cidadania preconizada pelos PCN. De fato, os autores desse documento sustentam explicitamente que "língua estrangeira no ensino fundamental é parte da construção da cidadania" (BRASIL, 1998, p. 41).

Contudo, percebemos, no PNLD, uma diretriz, para o desenvolvimento das quatro habilidades no ensino de línguas, que não aparece nos Parâmetros. Os PCN privilegiam a ênfase na leitura, considerando o trabalho com a escrita, audição e fala apenas nas situações em que estiverem disponíveis condições favoráveis para tal. Segundo esses referenciais, somente a ênfase na leitura parece atender a objetivos socialmente justificáveis, para a inclusão das línguas no ensino fundamental. Levando-se em conta a função social que as línguas desempenham na sociedade brasileira, os Parâmetros assumem que é muito reduzido o número de pessoas com real e contínuo acesso a um outro idioma em situações de comunicação, o que justificaria o foco no ensino de leitura. Além dos motivos de ordem social e didática, há, também, os de ordem estrutural, dentre os quais, a configuração do espaço físico e a organização dos alunos nesse ambiente, o que normalmente não favorece a interação oral.

Para avaliar a adequação do material didático, o Edital do PNLD 2011 (BRASIL, 2010), com base em critérios eliminatórios gerais e específicos, originou uma ficha de avaliação com 92 perguntas, divididas em 14 blocos, como temos discriminado no próprio $\mathrm{Guia}^{4}$. A análise dessa ficha de avaliação nos permite depreender a maneira pela qual o PNLD 2011 compreende a função do LD no ensino e, certamente, o papel que atribui à língua estrangeira no quadro escolar.

Dentre os critérios envolvidos na avaliação, encontram-se, também, critérios voltados para a análise do Manual do Professor. Percebemos, desse modo, uma certa preocupação com a formação docente, pois as perguntas do bloco $\mathrm{V}$, concernentes a esse material, trazem à tona aspectos relacionados à formação continuada do professor, tendo em vista, para além de sugestões de respostas das atividades, o fornecimento de insumo linguístico e informações culturais, bem como a promoção de reflexões acerca da prática pedagógica.

Como resume Costa (2011), sob a ótica do PNLD, para ser considerado aprovado, o LD precisa reunir todo um conjunto de atributos capazes de transformá-lo em uma ferramenta adequada de ensino no contexto educacional, tais como:

[...] respeitar a legislação e não veicular estereótipos e preconceitos ou difundir marcas, produtos e serviços; apresentar coerência entre a fundamentação teóricometodológica e o conjunto de textos e atividades que configuram o LA [livro do aluno]; observar as características e finalidades específicas do MP [manual do professor], dentre elas, contribuir para a ampliação dos conhecimentos do professor, discutir formas e instrumentos de avaliação e indicar possibilidades de trabalho interdisciplinar; ter estrutura editorial e projeto gráfico compatíveis com os objetivos didático-pedagógicos; apresentar uma organização que reflita a proposta pedagógica; prever a diversidade de contextos de ensino-aprendizagem; oferecer um conjunto de textos orais e escritos autênticos, verbais, não verbais e multimodais, representativos de diferentes gêneros e tipos textuais,esferas de atividade social e suportes; propor atividades de compreensão e produção oral e escrita, preferencialmente, de forma

${ }^{4}$ Esse material pode ser encontrado em <http://www.fnde.gov.br/programas/livro-didatico/guia-do-livro/item/2349-guia-pnld2011-\%E2\%80\%93-anos-finais-do-ensino-fundamental $>$. 
integrada,condizentes com as especificidades dos gêneros e com as formas como ocorrem as interações no mundo social; possibilitar o contato com e ouso de diferentes variantes linguísticas; apresentar conteúdos, informações e dados com correção e precisão; contextualizar a gramática e o vocabulário e favorecer o uso dos conhecimentos linguísticodiscursivos em práticas variadas e autênticas; retratar a diversidade social, étnico-racial e cultural dos usuários da LE. (COSTA, 2011, p. 334).

Evidentemente, temos, aqui, muitos e variados atributos colocados em cena, envolvendo aspectos não somente didáticos e pedagógicos, como já mencionado. O LD, com suas complexas características, assumindo conotações políticas, ideológicas, sociais, culturais e econômicas, realmente, envolve todas essas facetas, necessárias, de fato, para se promover um ensino consciente e comprometido com a realidade circundante. Podemos pensar, a princípio, que essa seria uma visão muito idealizada. Todavia, devemos ter em mente que focalizamos aqui a primeira avaliação do LD de língua estrangeira, cujo edital procurou "assentar as bases" do perfil que deveriam ter os LD que viessem a participar do processo de seleção, como ressalta Costa (2011).

Vale destacar que, já nesse primeiro momento, tão importante para o ensino de línguas, a oralidade recebe atenção específica nos parâmetros estabelecidos pelo PNLD. Em outras palavras, o Programa não negligenciou a oralidade, que, ainda, se constitui de uma questão "pouco falada", nos termos de Marcuschi (2005), no ensino de línguas na educação básica. Observemos, então, a seguir, como o PNLD 2011- Língua Estrangeira Moderna aborda essa problemática, com destaque para a produção oral, foco da nossa pesquisa.

\section{O PNLD e a Produção Oral}

O Guia do PNLD 2011 dedica um dos blocos da ficha de avaliação, o de número doze, à produção oral. São propostas as seguintes perguntas, como critérios de avaliação:

73. Existem oportunidades para o aluno usar diferentes estratégias de comunicação (verbais e não verbais)?

74. Existem possibilidades para o aluno se comunicar em situações diversas (conversação, entrevistas, debates, apresentação de trabalhos, dramatizações, leitura, inclusive de textos poéticos e outros gêneros orais)?

75. As atividades de produção oral permitem o uso de diversas funções comunicativas?

76. Existem oportunidades para o aluno discutir e escolher os registros, as variedades de linguagem e os itens lexicais adequados a cada situação comunicativa?

(BRASIL, 2010, p. 18).

Esse bloco (Produção oral), juntamente como os imediatamente anteriores, do número oito ao onze, contempla a análise dos textos que integram o LD. No caso do bloco doze, temos, então, o foco nos textos orais voltados para o desenvolvimento e ampliação das habilidades subjacentes à produção oral. Percebemos, inicialmente, que há uma preocupação não apenas com a linguagem verbal, mas, igualmente, com a não verbal (pergunta 73). Quando se trata de oralidade, o trabalho com a dimensão não verbal pode parecer óbvio, a princípio, mas sabemos que isso nem sempre se reflete no contexto da sala de aula. Deste modo, julgamos relevante que o documento enfatize essa questão. Afinal, ao se propor a inclusão da produção oral no quadro dos objetos ensináveis na escola, temos que levar em conta tanto a materialidade dos textos enquanto gêneros ${ }^{5}$ quanto as suas propriedades intrínsecas, próprias da modalidade da fala, para além da sua relação com a escrita, como aponta Teixeira:

Construir o oral como objeto de ensino-aprendizagem significa compreender que a oralidade se manifesta em textos vinculados a gêneros regidos por regras próprias de estilo, composição e temática. Será

${ }^{5}$ Dados os limites deste trabalho, adiante, trataremos, brevemente, da noção de gênero. 
preciso valorizar a entonação, considerando seu papel de abrir e fechar turnos, expressar emoções, marcar o acabamento ou a continuidade do fluxo verbal e perceber que "tomar a palavra está em relação íntima com o corpo" (SCHNEUWLY; DOLZ, 2004, p. 159) e, portanto, mímicas faciais, posturas, olhares e a gestualidade do corpo são aspectos incluídos nas atividades de expressão oral. (TEIXEIRA, 2012, p. 247).

Nesse sentido, as perguntas do Guia do PNLD 2011 (BRASIL, 2010) sugerem que o uso da língua deve se dar em variadas situações de comunicação, o que significa considerar, além da dimensão mais propriamente linguística, aspectos relativos à sua dimensão sociocultural (note-se, por exemplo, a preocupação com a adequação de registros e variedades de linguagem). Explorar os diversos elementos do contexto de produção, como os interlocutores envolvidos e os propósitos da interação, possibilitaria, assim, amenizar a artificialidade inerente ao contexto escolar, aproximando as propostas trazidas pelo LD de situações reais de comunicação oral.

Cumpre, também, salientar que as sugestões de produção oral no Guia do PNLD, ao contrário do que costuma acontecer nos LD mais tradicionais, vão além do diálogo, apontando para o uso de gêneros orais diferentes. São exemplificados gêneros como a entrevista, a apresentação de trabalho (algo que talvez pudesse se aproximar dos seminários escolares), o debate e gêneros da esfera literária, ou seja, a proposta é que se trabalhe não só com gêneros primários, mas, também, secundários. ${ }^{6}$

O bloco de número oito (Coletânea de textos orais e escritos) já evidencia esse foco nos gêneros e delimita a sua abordagem, mostrando-nos os aspectos que deveriam ser levados em conta na avaliação do LD. Preconiza-se o uso de gêneros representativos de esferas sociais diversas, provenientes de suportes, também, diversos (meios impresso e virtual), além da preocupação com a autenticidade dos textos, da sua relação com o mundo social, em uma tentativa de evitar, ou pelo menos tornar menos recorrente, o recurso aos textos fabricados, exclusivamente, para fins didáticos.

Ao nos apresentar as resenhas das obras de língua inglesa selecionadas ${ }^{7}$, o Guia traz, também, informações sobre dados dos LD referentes especificamente ao tratamento da produção oral. $\mathrm{Na}$ análise de ambas as coleções, encontra-se descrito, em termos de conteúdo, o que será trabalhado em cada um dos anos do ensino fundamental (sexto ao nono ano). Há, ainda, na seção de "análise da obra", informações voltadas à análise da produção oral no interior do LD, revelando-nos, por exemplo, qual o gênero mais focalizado ali. Por fim, temos a seção "na sala de aula", a qual, também, apresenta questões associadas à prática pedagógica no desenvolvimento do componente oral.

Observamos, diante do exposto, que a preocupação com a oralidade está presente de forma clara no PNLD 2011 de Língua Estrangeira. Acreditamos que esse aspecto pode contribuir, para que mais atenção seja dada à produção oral, permitindo que, apesar das dificuldades que, porventura, possam se apresentar, ao se efetuar um trabalho efetivo com a oralidade, esse tipo de atividade não seja totalmente negligenciado ou realizado de forma equivocada.

${ }^{6}$ Pela ótica bakhtiniana (BAKHTIN, 1997, p. 281), os gêneros diferenciam-se entre primários (simples) e secundários (complexos). Os primários são constituídos das formas de comunicação verbal espontânea e estão em relação direta com seu contexto mais imediato. Tratam-se dos gêneros ligados a esferas sociais da vida cotidiana (em geral, mas não exclusivamente, orais), em seus mais variados níveis, como os diálogos das reuniões sociais, o diálogo cotidiano, a conversa familiar, a carta pessoal. Os secundários, que se formam a partir da transmutação dos gêneros primários, aparecem em circunstâncias de uma comunicação cultural mais complexa, elaborada (em geral, mas não necessariamente, escrita) e de circulação nas esferas sociais públicas, como os gêneros que se usam nas atividades artísticas, científicas, sociopolíticas, filosóficas, de educação formal e assim por diante.

${ }^{7}$ Coleção Keep in Mind, da Editora Scipione, de autoria de Elizabeth Young Chin e Maria Lúcia Fernandes Abreu Zaorob, e coleção Links - English for Teens, da Ática, de autoria de Amadeu Onofre da Cunha Coutinho Marques e Denise Machado dos Santos. 
Tendo em vista o processo de transposição didática, notamos que as questões, anteriormente, enumeradas aqui podem nortear a transposição didática do componente oral, nos moldes do que se encontra estabelecido nos documentos oficiais. A adequação e eficácia, porém, de tal transposição, para o trabalho pedagógico eficiente do professor via LD, é um aspecto que deve ser levado em consideração e se dará de acordo com a concepção de linguagem e, consequentemente, de ensino-aprendizagem subjacente ao uso que se dará do LD em sala de aula.

Tomando como foco, agora, o PNLD 2014 Língua Estrangeira Moderna (BRASIL, 2013a), e analisando o Guia, mais uma vez, sob a ótica do desenvolvimento de habilidades orais, vemos que há uma considerável mudança, no que tange aos critérios a serem observados na abordagem da produção oral, tratada nesse documento como “expressão oral". O bloco VI apresenta perguntas especificamente voltadas para essa habilidade:

“23. Propõe práticas que possibilitam aos estudantes interagir significativamente na língua estrangeira"?

"24. Contém atividades relativas a diferentes situações comunicativas?”

Podemos observar aqui, de imediato, a redução do número de perguntas que visam a abordar a produção oral, o que aponta para um tratamento mais geral do componente oral no documento, devido, também, ao escopo mais amplo das perguntas formuladas. Notamos, ainda, que, embora se faça menção a "diferentes situações comunicativas", e o conceito de gênero possa estar subjacente, o termo "gênero" já não mais é enfatizado, como ocorria no Guia do PNLD 2011. Não há uma referência explícita a essa noção nessa parte das perguntas que compõem a ficha de avaliação pedagógica do documento em foco.

Nas resenhas das três coleções selecionadas pelo Programa - Alive!, de Vera Menezes, Kátia Tavares, Junia Braga e Claudio Franco, para o $6^{\circ}$ e $7^{\circ}$ anos, e Vera Menezes, Junia Braga e Claudio Franco, para $8^{\circ}$ e $9^{\circ}$ anos; It Fits, com Wilson Chequi como editor responsável, e Vontade de saber inglês, de Mariana Killner e Rosana Gemima Amancio -, a referência aos gêneros, também, não se dá de forma expressiva e clara, apesar de ocorrer na resenha do terceiro livro. Sabemos das dificuldades que perpassam o trabalho efetivo com os gêneros no ambiente escolar. Trata-se de uma tarefa árdua, é verdade; todavia, sabemos, também, da pertinência dessa noção no âmbito do ensino de línguas, para instrumentalizar os alunos a agirem no mundo com a linguagem. Ancorar as práticas pedagógicas de ensino de língua estrangeira nos gêneros se mostra, assim, um caminho interessante e produtivo. É o que veremos a seguir.

\section{O PNLD e a Noção de Gênero}

No campo dos estudos voltados ao ensino de língua, principalmente no que concerne ao ensino-aprendizagem de uma língua estrangeira, são crescentes as teorizações e discussões, com vistas à elaboração de uma abordagem de ensino calcada em princípios teóricos e metodológicos consistentes, voltados para as atividades de uso da língua não só no contexto escolar, mas, também, fora dele. Essa perspectiva discursiva encontrou, na noção de gênero, um aporte fundamental. Foge aos limites deste estudo, discutir o conceito de gênero em toda a sua complexidade, ou mesmo discutir diferentes visões, mas é preciso deixar claro que tomamos a perspectiva dialógica de linguagem do Círculo de Bakhtin, como nossa referência básica. $\mathrm{O}$ conceito em Bakhtin é diferente das teorias que entendem por gêneros apenas categorias formais, estruturas linguísticas ou classes fixas de textos: "Qualquer enunciado considerado isoladamente é, claro, individual, mas cada esfera de utilização da língua elabora seus tipos relativamente estáveis de enunciados, sendo isso que denominamos gêneros do discurso" (BAKHTIN, 1997, p. 279).

No cenário brasileiro, principalmente a partir de meados dos anos 90, o conceito de gênero passou 
a ocupar uma posição central no âmbito do ensino de línguas, materna ou estrangeira. Isso não quer dizer que práticas pedagógicas não orientadas por essa noção estejam necessariamente fadadas ao fracasso, entretanto, o grande volume de pesquisas desenvolvidas na área, após esse período, demonstra que se trata de um caminho, de fato, produtivo. Dionísio, Machado e Bezerra (2002), Lopes-Rossi (2002), Meurer e Motta-Roth (2002), Cristovão e Nascimento (2004), Karwoski, Gaydeczka e Brito (2005).

Pensando, de forma especial, no ensino de língua estrangeira, em nosso caso, o inglês, somos confrontados com o fato de que, inegavelmente, não se desenvolve um processo de ensino-aprendizagem com base em palavras ou frases descontextualizadas; ao contrário, um ensino comprometido com sua eficácia se pauta na produção e compreensão de textos, orais ou escritos. Não estamos assumindo, como já mencionado, que tomar o gênero como eixo norteador do programa didático-pedagógico seja o único caminho possível para um ensino eficaz. A seleção de textos pode se dar em função de determinadas temáticas, por exemplo, oportunizando discussões e atividades interessantes. Defendemos, contudo, que a abordagem dos textos, dentro de um enquadre de gêneros, pode representar uma perspectiva bastante adequada no ensino de língua. Afinal, como sustenta Marcuschi (2008), se a comunicação se efetua através de textos, é apenas por meio dos gêneros que os textos tomam forma: "é impossível não se comunicar verbalmente por algum gênero, assim como é impossível não se comunicar verbalmente por algum texto" (MARCUSCHI, 2008, p. 154). Nesse sentido, para inserir o aprendiz dentro do mundo social que o cerca, constituído por práticas de linguagem, as ações de ensino podem encontrar nos gêneros ferramentas com grande poder de atuação.

Os documentos e programas oficiais de ensino, dentro do qual destacamos o PNLD, alinhados com essa visão, propõem, então, que as concepções que subjazem aos objetivos do ensino de língua e ao LD, o qual se configura, muitas vezes, como o principal mediador das práticas pedagógicas dos professores na sala de aula, estruturem-se de maneira a fornecer ao aprendiz amostras de linguagem contextualizadas e relacionadas a práticas discursivas genuínas em contextos diversificados, capacitando-o a atuar em situações de comunicação do mundo social. Esses documentos nos remetem, desse modo, à noção de gênero, a qual pode se apresentar como um importante instrumento pedagógico para o ensino de língua.

\section{Procedimentos Metodológicos}

Com o objetivo de investigar em que medida os critérios relacionados à produção oral presentes no PNLD - Língua Estrangeira Moderna são atendidos na abordagem do LD de língua inglesa, analisamos, neste trabalho, o último volume da coleção Links English for Teens. Como mencionado, essa coleção foi aprovada no processo de avaliação do PNLD 2011, e sua escolha, como objeto de investigação, justifica-se pelo fato de ser amplamente adotada em escolas públicas de Juiz de Fora, Minas Gerais, cenário privilegiado de nossas pesquisas.

Cada um dos quatro volumes dos anos finais do ensino fundamental dessa coleção possui dez unidades temáticas, cada uma dividida da seguinte maneira: Let's Read, Let's Listen, Let's Speak, Grammar in Action, Grammar Notes, Words in Action, Let's Write, Let's Play e Let's Stop and think.

Ao final de cada livro, há um workbook com atividades de gramática e vocabulário, onde encontramos, também, quadros para autoavaliação da aprendizagem (self-evaluation). Logo após, temos um glossário e, por fim, o manual do professor, onde encontramos uma descrição da obra como um todo e, também, da estrutura e organização das unidades. Há, nessa seção, uma explicitação dos aspectos teórico-metodológicos relacionados aos recursos e estratégias de ensino a serem adotados. 
Selecionamos, neste trabalho, o volume do nono ano, a fim de observar como a produção oral é abordada no último ano do ensino fundamental, o que nos possibilitaria ter uma visão do final do processo de ensino na educação básica.

Dentro do paradigma de pesquisa qualitativa, de cunho interpretativista, recorremos à pesquisa documental, uma vez que não só documentos do PNLD de Língua Estrangeira Moderna serão estudados, mas o próprio LD será tomado como um documento para análise. Dados quantitativos não serão desprezados (por exemplo, o número de gêneros orais selecionados em cada volume), embora nos interesse especialmente a apreensão dos significados subjacentes ao material analisado. Pode-se justificar a pertinência da pesquisa documental, nesse caso, pelo fato de tal perspectiva, de acordo com Ludke e André (1986), constituir uma tarefa importante na abordagem qualitativa, seja complementando informações obtidas por outras técnicas, seja desvelando aspectos novos de um tema ou problema. Assim, o presente estudo analisa um aspecto específico presente no LD, a produção oral, sob a luz de um aparato teórico, também, específico, buscando um novo olhar sobre tal material, que já foi alvo de avaliação.

Focalizamos a seção que os autores do LD assumem como sendo, especificamente, dedicada à produção oral, a seção Let's Speak, observando se as atividades propostas apresentam um enquadre adequado de gênero e de tratamento da oralidade, aproximando-se do que estabelecem, de forma geral, os critérios presentes no Guia do PNLD 2011 (BRASIL, 2010).

O primeiro passo de nossa análise se dá pela observação do que é tratado em cada unidade do volume do $9^{\circ}$ ano da coleção, uma vez que é de suma importância entender como cada volume estrutura suas unidades, pois "é a mediação destas unidades, por parte de professores e alunos, que colabora na construção do conhecimento e na aprendizagem" (TILIO, 2012, p. 221-222). Passamos, em seguida, à discussão das atividades direcionadas à produção oral e da própria forma de abordagem dos gêneros.

Cumpre ressaltar que a análise, aqui apresentada, é um recorte de uma pesquisa maior, desenvolvida na linha Linguística e Ensino de Língua do Programa de Pós-Graduação em Linguística da Universidade Federal de Juiz de Fora (UFJF). ${ }^{8}$

\section{Análise dos Dados}

Com o objetivo de obter uma visão geral do que é tratado em cada unidade do $9^{\circ}$ ano, elaboramos um quadro com os conteúdos de cada unidade do volume selecionado, dividindo-os em vocabulário, comunicação e tema transversal, categorias baseadas na tabela de conteúdos (Contents) presente no início do próprio livro em análise.

\footnotetext{
${ }^{8}$ Entre outros trabalhos, tal pesquisa resultou na Dissertação de Mestrado de Lombardi (2014), intitulada "A produção oral sob a perspectiva dos gêneros textuais e do letramento no livro didático de língua inglesa".
} 
Quadro 1 - Organização das unidades no livro do $9^{\circ}$ ano.

\begin{tabular}{|c|c|c|c|}
\hline UNIDADE & VOCABULÁRIO & COMUNICAÇÃO & $\begin{array}{c}\text { TEMA } \\
\text { TRANSVERSAL }\end{array}$ \\
\hline $\begin{array}{c}\text { l } \\
\text { What do you do } \\
\text { for a living? }\end{array}$ & $\begin{array}{l}\text { Expressóes úteis no } \\
\text { contexto escolar; } \\
\text { profissões. }\end{array}$ & $\begin{array}{l}\text { Pedindo informaçóes sobre } \\
\text { outra pessoa. }\end{array}$ & $\begin{array}{l}\text { Etica e trabalho - A } \\
\text { importância do inglês no } \\
\text { mercado de trabalho no } \\
\text { Brasil. }\end{array}$ \\
\hline $\begin{array}{c}2 \\
\text { The world of } \\
\text { fashion }\end{array}$ & Phrasal verbs. & Expressando opiniăo. & $\begin{array}{l}\text { Etica e consumismo: a } \\
\text { moda através dos } \\
\text { tempos. }\end{array}$ \\
\hline $\begin{array}{c}\text { 3 } \\
\text { What's new? }\end{array}$ & $\begin{array}{l}\text { American } \\
\text { English/British } \\
\text { English. }\end{array}$ & Falando sobre objetos. & Etica-Exclusăo digital. \\
\hline $\begin{array}{c}4 \\
\text { A cleaner planet }\end{array}$ & Palavras homónimas. & $\begin{array}{l}\text { Pedindo es clarecimento sobre } \\
\text { o significado de uma palavra. }\end{array}$ & $\begin{array}{l}\text { Meio ambiente - ideias } \\
\text { para a preservação do } \\
\text { planeta. }\end{array}$ \\
\hline $\begin{array}{c}5 \\
\text { Our small world }\end{array}$ & Adjetivos. & $\begin{array}{l}\text { Dando opinióes e justificando- } \\
\text { as. }\end{array}$ & $\begin{array}{l}\text { Cidadania } \\
\text { multiculturalismo- } \\
\text { Representações do Brasil } \\
\text { e dos brasileiros. }\end{array}$ \\
\hline $\begin{array}{c}6 \\
\text { Teens have a } \\
\text { voice }\end{array}$ & Homófonos. & Falando sobre sentimentos. & $\begin{array}{lll}\text { Trabalho e ética - } & \text { e } \\
\text { trabalho infantil e } \\
\text { juvenil. }\end{array}$ \\
\hline $\begin{array}{c}7 \\
\text { Communication }\end{array}$ & Palavras confusas. & $\begin{array}{l}\text { Expressando sentimento e } \\
\text { opiniäo. }\end{array}$ & $\begin{array}{l}\text { Multiculturalismo- } \\
\text { linguagem não verbal. }\end{array}$ \\
\hline $\begin{array}{c}\mathrm{8} \\
\text { Let's make it a } \\
\text { better world! }\end{array}$ & $\begin{array}{l}\text { Formaçåo de } \\
\text { adjetivos: sufixo - } \\
\text { er. }\end{array}$ & Falando sobre o futuro. & $\begin{array}{l}\text { Etica e cidadania - } \\
\text { reflexão sobre o papel da } \\
\text { participação individual } \\
\text { na sociedade. }\end{array}$ \\
\hline $\begin{array}{c}9 \\
\text { Relationships }\end{array}$ & $\begin{array}{l}\text { Expressóes } \\
\text { relativas a } \\
\text { relacionamentos. }\end{array}$ & Expressando opiniäo. & $\begin{array}{l}\text { Etica - violéncia contra a } \\
\text { mulher; relacionamentos } \\
\text { em areas urbanas e } \\
\text { rurais. }\end{array}$ \\
\hline $\begin{array}{c}10 \\
T \text { is for teens. } T \\
\text { is for talent. }\end{array}$ & $\begin{array}{l}\text { Verbos e seus } \\
\text { complementos. }\end{array}$ & $\begin{array}{l}\text { Perguntando e respondendo } \\
\text { sobre pessoas famosas. }\end{array}$ & $\begin{array}{l}\text { Multiculturalismo e Etica } \\
\text { - o que é talento. }\end{array}$ \\
\hline
\end{tabular}

Fonte: Marques e Santos (2009).

Vale notar, aqui, que os conteúdos presentes em comunicação se evidenciam, segundo o manual do professor, como os aspectos a serem tratados na seção Let's Speak, específica para o trabalho de produção oral. A análise do quadro revela-nos a proposta de se abordarem funções que se aproximam bastante das variadas funções comunicativas que desempenhamos em nossa vida cotidiana, como "expressar opinião" (unidades 2 e 9), "justificar opiniões" (unidade 5) e "falar sobre sentimentos" (unidade 6). Isso nos remete a uma das perguntas da ficha de avaliação do Guia do PNLD 2011 (BRASIL, 2010), a de número 75: As atividades de produção oral permitem o uso de diversas funções comunicativas? Por outro lado, a própria apresentação dos conteúdos no início do livro, tal como exposto na tabela de conteúdos, não tem relação com gêneros, o que é um indício claro de que o LD não prioriza a abordagem de gêneros. 
Quanto às atividades propriamente ditas, observamos que elas se organizam, na seção em foco, em uma sequência de escuta, leitura e dramatização, fornecendo exercícios que giram em torno de um diálogo escrito que os alunos ouvem, leem e, logo após, dramatizam em duplas, ou tomam como modelo para executarem uma outra tarefa, em uma atividade do tipo Now in pairs [...].Com isso, percebemos a dependência que o oral, ainda, mantém em relação à escrita, evidenciando uma oralização da escrita, nos termos de Marcuschi (1997) e Schneuwly (2004), já que a reflexão sobre a modalidade falada da língua se fundamenta em um texto escrito e não diretamente na palavra falada, partindo-se da escrita para se promover o oral. Certamente, que fala e escrita interagem, e o fato das atividades se apoiarem num texto escrito não é, necessariamente, um aspecto negativo, mas o que estamos discutindo aqui é que o trabalho com a oralidade parece, na verdade, um pretexto para a abordagem da modalidade escrita da língua. Além disso, pode-se problematizar a própria natureza da atividade, na medida em que a questão da dramatização parece indicar uma visão, ainda, bastante tradicional de ensino da oralidade.

Apesar de contarem com a parte de escuta, as atividades, de um modo geral, não se ancoram na produção falada real, ou seja, na audição de falas provenientes de contextos mais autênticos, não apenas "fabricados" para fins pedagógicos. A atividade de escuta, que, de fato, é a audição do texto escrito fornecido para aquele exercício, volta-se para a repetição e/ou dramatização das sentenças, para a identificação de expressões a serem trabalhadas, assim como para a observância da entonação e da pronúncia correta das palavras, não se privilegiando a compreensão. Apenas em uma unidade deste volume, a de número 7 , pudemos observar uma abordagem do componente oral que não recorre à escrita, fornecendo base para a produção oral por meio de situações reais ou potenciais de interlocução. Todavia, essa abordagem só aparece uma única vez ao longo do $\mathrm{LD}$ do $9^{\circ}$ ano.
Quanto aos gêneros, mais especificamente, os gêneros orais, podemos constatar que, minimamente, as atividades em Let's Speak demonstram alguma preocupação com a noção de gênero, embora não haja a diversidade desejável nem uma abordagem muito adequada. Segundo o Guia do PNLD 2011Língua Estrangeira, temos nessa seção os seguintes exemplares: entrevista; diálogo; checar significado de uma palavra; justificar opiniões; falar sobre sentimentos (BRASIL, 2010, p. 45). Por essa descrição, identificamos apenas dois gêneros, a entrevista e o diálogo; os demais se associam a funções comunicativas, o que é outro indício de que a coleção não se orienta verdadeiramente pela abordagem de gêneros.

Observemos como os gêneros se distribuem no decorrer deste volume:

Quadro 2 - Gêneros orais no livro do $9^{\circ}$ ano.

\begin{tabular}{|c|c|}
\hline UNIDADE & GENERO ORAL \\
\hline $\mathbf{1}$ & Entrevista \\
\hline $\mathbf{2}$ & Diálogo \\
\hline $\mathbf{3}$ & Diálogo \\
\hline $\mathbf{4}$ & Diálogo \\
\hline $\mathbf{5}$ & Diálogo \\
\hline $\mathbf{6}$ & Entrevista \\
\hline $\mathbf{7}$ & Diálogo \\
\hline $\mathbf{8}$ & Diálogo \\
\hline $\mathbf{9}$ & Fónum de discussão/diálogo \\
\hline $\mathbf{1 0}$ & Diálogo \\
\hline
\end{tabular}

Fonte: Brasil (2010).

Para além dos gêneros elencados pelo Guia (BRASIL, 2010), há, ainda, o fórum de discussão, um gênero escrito que admite uma interface com os gêneros orais, como vemos na unidade 9. A presença desses gêneros vai ao encontro do critério estabelecido pela pergunta de número 74 Existem possibilidades para o aluno se comunicar em situações diversas (conversação, entrevistas, debates, apresentação de trabalhos, dramatizações, 
leitura, inclusive de textos poéticos e outros gêneros orais)? - instrumentalizando o aluno, mesmo que de forma um tanto incipiente, dada a estrutura das atividades, a se expressar oralmente. Apesar das limitações encontradas, é sempre melhor que haja algum enquadre de gêneros do que tratar a produção oral de forma descontextualizada. É nesse sentido que Dolz e Schneuwly defendem o uso dos gêneros como um caminho para estruturar o ensino do oral: "A ação de falar realiza-se com a ajuda de um gênero, que é um instrumento para agir linguisticamente" (DOLZ; SCHNEUWLY, 2004, p. 171).

Percebemos, ainda, ao analisar o quadro acima, a predominância do gênero diálogo. As atividades que se organizam em torno desse gênero, ainda, seguindo o padrão escuta-leitura-dramatização já mencionado, não abordam de maneira satisfatória a dimensão social do gênero. Isso equivale a dizer que a abordagem aqui utilizada não possibilita o tratamento da face sociocultural do gênero diálogo, uma vez que não abre espaço para uma conversação fora da estrutura de um diálogo fabricado para fins didáticos. A grande maioria das atividades em Let's Speak não propicia que sejam enfatizados os aspectos sociais e culturais que, certamente, subjazem à estrutura do gênero, como podemos notar pelos enunciados apresentadas na unidade 7 :

1 - Look at the picture and listen to the three dialogues on the CD. Then answer: Which of the dialogues matches the picture? How do you know?

2 - Act out the 3 dialogues in pairs. To answer the question in the balloon, choose three different feelings and use the adequate tone of voice and facial expression.

Embora observemos a atenção dada a algumas características da modalidade falada, como o tom de voz e a expressão facial, capazes de exprimir sentimentos diferentes, não sendo algo associado e transmitido pelo código linguístico em si, vemos que isso ocorre de forma um tanto descontextualizada, sem menção ao contexto de produção ou de circulação de tal manifestação oral. $\mathrm{O}$ enunciado sugere o auxílio de uma figura que poderia, a princípio, servir para contextualizar a situação, mas não há instrução alguma no LD que nos leve a perceber uma preocupação com essa questão. A expressão dos sentimentos no exercício 2 poderia se dar dentro de contextos mais claros, como em uma conversa entre os alunos sobre um evento na escola ou um convite feito a um colega para alguma programação na cidade, por exemplo. No entanto, como sugerem as instruções para o professor, deve-se seguir uma determinada estrutura como modelo e, para cada resposta, o aluno deverá, necessariamente, usar um sentimento diferente e registrá-lo na tabela ali fornecida; a atividade resulta, mais uma vez, em um texto escrito. O professor deve, ainda, pedir aos alunos para dramatizarem o diálogo para seus colegas, que deverão identificar os sentimentos expressos: Are they happy? Excited? Angry? Sleepy? Tired? Tudo isso com base, apenas, na pergunta solta fornecida no exercício (Can you go to the movies?), como vemos a seguir.

Figura 1 - Atividade de produção oral no livro do $9^{\circ}$ ano.

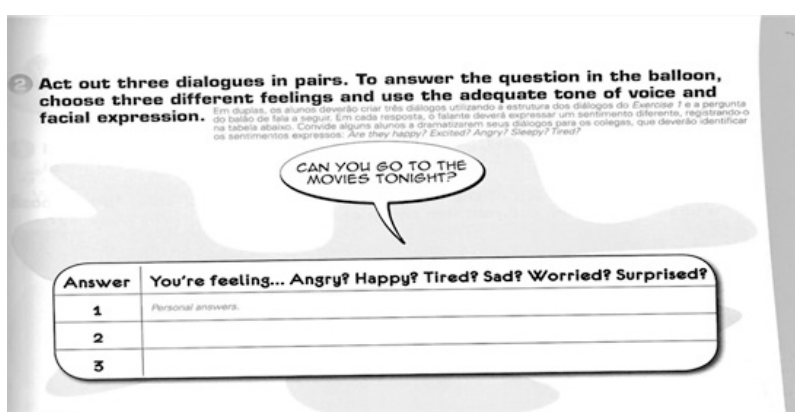

Fonte: Marques e Santos (2009).

Conforme se pode notar, a proposta até possibilita um trabalho com a linguagem não verbal, mas o diálogo não é efetivamente explorado enquanto gênero. Não basta pedir aos alunos para "falarem", pois, sem uma situação de produção claramente estabelecida, sem um propósito definido a ser levado a cabo pela interação, a atividade corre o risco de ser apenas uma prática oral das estruturas ensinadas. Não podemos perder de vista que "a mera oralidade 
não caracteriza pedagogicamente a atividade de uso da linguagem em situações formais e informais de comunicação oral" (TEIXEIRA, 2012, p. 242).

Nas unidades que trazem o gênero entrevista, as unidades 1 e 6 , como vemos no quadro apresentado anteriormente, percebemos que a dimensão social do gênero, também, não é abordada de forma adequada. $\mathrm{Na}$ unidade 1 , temos evidenciado, claramente, o padrão escuta-leitura-dramatização. No primeiro exercício, há uma entrevista com o pai de Zedu, aluno da professora inglesa Jane, outra personagem que conduz os temas. Essa entrevista deve ser tomada como modelo no segundo exercício, para que os alunos entrevistem a mãe de Zedu, contando com as informações fornecidas. Apesar de haver, em alguma medida, a definição dos papéis dos participantes na interação, ainda, fazse necessária uma exploração maior do contexto, para que a situação fique menos artificial. A forma como o LD expressa o que deve ser feito, através de seu enunciado, não contribui devidamente para a explicitação do contexto de produção do gênero, tal como circula socialmente, nem para a observação da atitude responsiva ${ }^{9}$ dos interlocutores, ou seja, de como reagem frente ao ato comunicativo que a eles se apresenta.

Outro aspecto, que nos chama a atenção na unidade 1, reside nas instruções dadas ao professor:

Em duplas, os alunos deverão simular uma entrevista com a mãe de Zedu, usando as perguntas e as reações de Roxanna no diálogo do Exercise 1. Escolha uma ou duas duplas para dramatizar a entrevista à frente da classe. Como tarefa para casa, peça aos alunos que registrem a entrevista completa no caderno.

Vemos, neste exemplo, a referência explícita à geração de um texto escrito. Em uma seção de produção oral, não precisa, necessariamente, haver esse tipo de atividade, a não ser que a integração com a escrita se dê de forma mais significativa para a aprendizagem. A transcrição não parece ser pertinente nesse caso, já que as instruções não apresentam um propósito relevante para a sua realização, a não ser o treino de determinadas estruturas aprendidas na unidade. A atividade de registro da entrevista seria bem aplicada, se houvesse, por exemplo, uma sensibilização dos alunos quanto à questão da circulação do gênero entrevista. Certamente, não estamos propondo que se trate o aprendiz como um especialista em gêneros, contudo, é válido leválo a refletir sobre diferentes tipos de entrevistas e sobre algumas de suas características linguísticas e sociodiscursivas. Supõe-se que os alunos já estariam familiarizados com a entrevista jornalística, por exemplo, o que ampliaria a discussão em torno do gênero.

Concluímos, assim, com base nos dados analisados, que alguns gêneros orais são usados no LD do $9^{\circ}$ ano, mas a sua abordagem, ainda, requer mudanças, para que se possa dar conta dos aspectos não apenas linguísticos ali envolvidos. $\mathrm{O}$ volume atende, em linhas gerais, ao que está determinado para a seção de produção oral, conforme o Guia do PNLD 2011 (BRASIL, 2010); no entanto, as atividades se apresentam, ainda, de forma um tanto estrutural e, por vezes, pouco autêntica, não propiciando ao aprendiz práticas reais ou potencialmente reais de uso da língua, que seriam mais próximas de suas práticas sociais. Em suma, parece que o objetivo do LD não era o de explorar a língua como prática social, mas sim, como estruturas linguísticas, e, talvez por isso, o foco das atividades recaia sobre elementos linguísticos a serem praticados em diálogos produzidos pelos alunos por escrito e dramatizados.

\footnotetext{
${ }^{9}$ De acordo com a perspectiva dialógica de linguagem, qualquer que seja o tipo de enunciado, busca-se sempre uma resposta ao que já foi dito sobre o mesmo objeto ou problema, entendendo-se resposta aqui no sentido lato. Afirma Bakhtin que "todo enunciado se elabora como que para ir ao encontro dessa resposta" (BAKHTIN, 1997, p. 320), dessa compreensão responsiva ativa do outro.
} 


\section{Considerações Finais}

Mesmo obedecendo, em certa medida, ao que está proposto no Guia do PNLD 2011, com vistas, particularmente, ao trabalho com a produção oral, as atividades do LD analisado, ainda, são bem estruturais, promovendo situações de uso da língua pouco significativas, em termos de comunicação, o que acabaria acentuando a artificialidade que já é própria do contexto da escola. As atividades propostas parecem não ter o propósito de real inserção social. Do ponto de vista da estrutura dos enunciados expressos no LD, por exemplo, fica claro que essas atividades não transcendem muito o propósito didático de ensinar estruturas da língua (ou de ensinar sobre a língua). Não são, geralmente, estabelecidas oportunidades, para que o aluno use a língua, tendo em vista o mundo real que vai além dos limites da escola, afastando-se, desse modo, daqueles diálogos fabricados quase que com o único objetivo de empregar os aspectos gramaticais em foco em uma determinada unidade do LD. Embora, neste recorte, tenhamos discutido dados somente do último ano do ensino fundamental, a análise dos outros livros da coleção não leva a resultados muitos diferentes.

De todo modo, constatamos que o LD de língua estrangeira se configura como um instrumento potencialmente muito importante para se efetuar um trabalho de produção oral. A forma de abordagem dos gêneros e as atividades em torno desses gêneros poderiam, certamente, ser expandidas e adaptadas pelo professor. $\mathrm{O}$ ponto crucial que se apresenta, então, é que a produção oral, ainda que com restrições e inadequações, não tem sido mais negligenciada no contexto da escola básica. Os documentos e programas oficiais, como o próprio PNLD, reconhecem a sua relevância e vêm se organizando de maneira a elaborar um tratamento adequado do componente oral na sala de aula de língua estrangeira. Trabalho difícil, mas que, com o que vimos aqui, já foi iniciado. É inegável que o LD deu um salto de qualidade a partir dessas políticas educacionais. Precisamos, agora, avançar, reivindicando LD cada vez melhores, que considerem efetivamente as práticas sociais de uso da língua estrangeira na contemporaneidade.

\section{Referências}

BAKHTIN, M. Estética da criação verbal. São Paulo: Martins Fontes, 1997.

BRASIL. Ministério da Educação. Secretaria de Educação Básica. Guia de livros didáticos: PNLD 2011: língua estrangeira moderna. Brasília, 2010. Disponível em: <http:/www.fnde.gov.br/programas/ livro-didatico/guia-do-livro/item/2349-guiapnld-2011-\%E2\%80\%93-anos-finais-do-ensinofundamental>. Acesso em: 19 out. 2012.

. Guia de livros didáticos: PNLD 2014: língua estrangeira moderna. Brasília, 2013a. Disponível em: $\quad<$ http://www.fnde.gov.br/programas/livrodidatico/guia-do-livro/item/2349-guia-pnld-2011$\% \mathrm{E} 2 \% 80 \% 93$-anos-finais-do-ensino-fundamental>. Acesso em: 6 jun. 2013.

. Parâmetros curriculares nacionais: terceiro e quarto ciclos do ensino fundamental: língua estrangeira. Brasília, 1998.

\section{Programa Nacional do Livro Didático} (PNLD): apresentação. 2013b. Disponível em: http:// portal.mec.gov.br/index.php? Itemid=668\&id=12391 \&option $=$ com_content\&view=article. Acesso em: 3 nov.2013.

CHIN, E. Y.; ZAOROB, M. L. F. A. Keep in mind. São Paulo: Scipione, 2009.

COSTA, E. G. M. Lugar de aprender língua estrangeira é na escola: reflexões em torno do PNLD 2011. Letras, Santa Maria, v. 21, n. 42, p. 315-340, jan./jun. 2011.

CRISTOVÃO, V. L. L.; NASCIMENTO, E. L. (Org.) Gêneros textuais: teoria e prática. Londrina: Moriá, 2004.

DIONÍSIO, A. P.; MACHADO, A. R.; BEZERRA, M. A.. (Org.). Gêneros textuais e ensino. Rio de Janeiro: Lucerna, 2002. 
DOLZ, J; SCHNEUWLY, B. O oral como texto: como construir um objeto de ensino. In: SCHNEUWLY, B.; DOLZ, J. (Org.). Gêneros orais e escritos na escola. Campinas: Mercado de Letras, 2004. p. 149-185.

KARWOSKI, A. M.; GAYDECZKA, B.; BRITO, K. S. (Org.). Gêneros textuais: reflexões e ensino. União da Vitória: Kaygangue, 2005.

LOPES-ROSSI, M. A. G. (Org.). Gêneros discursivos no ensino de leitura e produção de textos. Taubaté: Cabral, 2002.

LÜDKE, M.; ANDRÉ, M. Pesquisa em educação: abordagens qualitativas. São Paulo: Ed. EPU, 1986.

MACHADO, A. R; CRISTOVÃO, V. L. L. A Construção de modelos didáticos de gêneros: aportes e questionamentos para o ensino de gêneros. Linguagem em (Dis)curso: LemD, Tubarão, v. 6, n. 3, p. 547-573, set./dez. 2006.

MARCUSCHI, L. A. Concepção de língua falada nos manuais de português de $1^{\circ}$ e $2^{\circ}$ graus: uma visão crítica. In: REUNIAO ANUAL DA SBPC, 49., Belo Horizonte, 1997. Trabalhos em Linguística Aplicada, Campinas, v. 30, p. 39-79, 1997.

- Oralidade e ensino: uma questão pouco falada. In: DIONÍSIO, A. P.; BEZERRA, M. A. (Org.). O Livro didático de Português: múltiplos olhares. 3. ed. Rio de janeiro: Lucerna, 2005. p.21-34.

- A produção textual, análise de gêneros e compreensão. São Paulo: Parábola, 2008.

MARQUES, A. O. C. C.; SANTOS, D. M. Links: English for teens, São Paulo: Ática, 2009.

MEURER, J. L.; MOTTA-ROTH, D. (Org.). Gêneros textuais e práticas discursivas: subsídios para o ensino da linguagem. Bauru: EDUSC, 2002.

PINTO, A. P.; PESSOA, K. N. Gêneros textuais: professor, aluno e livro didático de língua inglesa nas práticas sociais. In: DIAS, R.; CRISTOVÃO, V. L. L. (Org.). O livro didático de língua estrangeira: múltiplas perspectivas. Campinas: Mercado de Letras, 2009. p. 79-98.
RAMOS, R. C. G. O livro didático de língua inglesa para o ensino fundamental e médio: papéis, avaliação e potencialidades. In: DIAS, R.; CRISTOVÃO, V. L. L. (Org.). O livro didático de língua estrangeira: múltiplas perspectivas. Campinas: Mercado de Letras, 2009. p. 173-198.

SCHNEUWLY, B. Palavra e ficcionalização: um caminho para o ensino da linguagem oral. In: SCHNEUWLY, B.; DOLZ, J.. Gêneros orais e escritos na escola. Campinas: Mercado de Letras, 2004. p. 129-147.

SIQUEIRA, S. Se o inglês está no mundo, onde está o mundo nos materiais didáticos de inglês? In: SCHEYERL, D. SIQUEIRA, S. (Org.). Materiais didáticos para o ensino de línguas na contemporaneidade: contestações e proposições. Salvador: EDUFBA, 2012. p. 311-354.

TEIXEIRA, L. Gêneros orais na escola. Bakhtiniana, São Paulo, v. 7, n. 1, p. 240-252, jan./jun. 2012.

TILIO, R. Os gêneros do discurso e o livro didático de inglês: algumas considerações. In: DIAS, R.; DELL'ISOLA, R. L. P. Gêneros textuais: teoria e prática de ensino em LE. Campinas: Mercado de Letras, 2012. p. 205-236.

VIAL, A. P. S.; SILVA, J. Z. A inclusão das línguas estrangeiras modernas no Programa Nacional do Livro Didático (PNLD). Revista Bem Legal, Porto Alegre, v. 2, n. 1, p. 110-118, 2012.

Recebido em:26 abr. 2014. Aceito em: 2 jun. 2014. 
